\title{
Prediction in sustainable development capacity of water resources
}

\author{
Yu Guo \\ School of North China Electric Power University, Baoding 071000, China
}

\begin{abstract}
In accordance with the variation, this paper divides the indexes for sustainable development of water resources into five categories. And the appropriate forecasting methods to predict the direction of the data in future is given, to lay the foundation for further study of changes in sustainable development capacity of water resources. Then the paper takes Libya for an example. Combing with the fuzzy comprehensive evaluation model and the prediction methods given below, we finally get Libya's future sustainable development capacity of water resources. The case further validates the reasonability of prediction methods, which improves the use of historical data in the current system when assessing the water capacity. We hope there is a certain reference value.
\end{abstract}

KEYWORD: sustainable development capacity of water resources, Index Classification, Prediction Model

\section{INTRODUCTION}

There has been a shortage of water resources in China for a long time, with low water use efficiency and widespread waste, which seriously hampered the overall sustainable development of economy and society. Therefore, the whole world are facing sustainable water resource challenges. We evaluate the carrying capacity of water resources, to determine the sustainability of water resources. Most studies nowadays select reasonable indicator system and use historical data to assess the sustainability of water resources. In accordance with the value change, this paper divides the indexes for sustainable development of water resources into five categories. And the appropriate forecasting methods to predict the direction of the data in future is given, to lay the foundation for further study of changes in sustainability of water resources. It is the common sense that the value of indicators is dynamic as time flies. Some are decreasing. For example, rainfall is decreasing with the global warming trend. Some are increasing. For example, industrial demand is greatly getting bigger with the development of the economics. Some have the high correlation with other factors. For example,
Water Pollution Ratio has much to do with Industrial Use. While others change little. For example, the surface water changes little because the geological and terrain is essentially the same in a period of time.

As for various kinds of indicators, we use different models to describe the dynamic change, to get the modified value of the indicators. Four prediction models (Time-series Model, Grey Prediction, Logistic Curve-fitting Model and Regression Analysis Model) are used to describe the dynamic nature of different indicators. Limited to space, we will simplify the introduction of the model. Finally, the paper gives a case to test and verify our model.

\section{PREDICTION MODEL}

\subsection{Index Selection}

Firstly, with reference to the paper ${ }^{[1]}$, we build the indicator system: target layer, criteria layer and index layer. Through the data provided by the Food and Agriculture Organization of the United Nations (FAOUN) ${ }^{[2]}$, we carefully select the typical 12 indicators as index layer. The indicator system is shown in table 1. 


\begin{tabular}{|c|c|c|}
\hline target layer & criteria layer & index layer \\
\hline \multirow{5}{*}{ Supply } & National Rainfall(mm/year) & National Rainfall(mm/year) \\
\hline & $\begin{array}{c}\text { Surface and Ground Water Ertering } \\
\text { the Country }\left(\mathrm{m}^{\wedge} 3 / \text { year }\right)\end{array}$ & $\begin{array}{c}\text { Surface and Ground Water Ertering } \\
\text { the Country }\left(\mathrm{m}^{\wedge} 3 / \text { year }\right)\end{array}$ \\
\hline & Water Withdrawal(m^3/year) & Water Withdrawal(m^3/year) \\
\hline & Sewage Treatment Capacity(\%) & Sewage Treatment Capacity(\%) \\
\hline & Water Pollution Ratio (\%) & Water Pollution Ratio (\%) \\
\hline \multirow{7}{*}{ Demand } & \multirow{3}{*}{ Agriculture } & Agriculture Use $\left(\mathrm{m}^{\wedge} 3\right)$ \\
\hline & & Total Cultivated Area $\left(\mathrm{m}^{\wedge}{ }^{2}\right)$ \\
\hline & & Agriculture, value added to GDP(\%) \\
\hline & \multirow{3}{*}{ Domestic } & Household use \\
\hline & & Population Density \\
\hline & & GDP per capita \\
\hline & Industrial Use & Industrial Use \\
\hline
\end{tabular}

\subsection{Index Classification and the Prediction Model}

Apart from the indicators with little change, we divide the indicators into four other kinds. To well reflect the dynamic characteristic, we use four different prediction models to different indicators. The detailed classification and its prediction model is as follows.

\subsubsection{Sort one}

The following indicators are constant, together with reasons.

1)Surface and Ground Water Entering the Country: The indicator is mainly determined by geographical factors with little change when we ignore the interference of external factors.

2)Sewage Treatment Capacity: Data given by UN shows the same high level for years.

3)Total Cultivated Area: Ignoring the influence of turmoil and war, we consider it constant.

4)Agriculture, value added to GDP: Libya develops agriculture a lot, so we consider it constant.

Hence, no model is used for indicator in this sort.

\subsubsection{Sort two with Time-series Model ${ }^{[4]}$}

The following indicators are increasing in a line, together with reasons.

1)Water Withdrawal: Data given by UN shows the ability of withdrawal is increasing in a line.

2)National Rainfall: We use the linear trends (the same as the former) because the climate changes little.

3)Population Density: the linear trend of increasing is applied to the reality more than $\mathrm{S}$ trend.

We use the Second Multinomial Exponential Smoothing model to predict the indicator with a linear trend. The formula is:
$\hat{y}_{t+T}=a_{t}+b_{t} T, T=1,2, \cdots$

$\left\{\begin{array}{l}a_{t}=2 S_{t}^{(1)}-S_{t}^{(2)} \\ b_{t}=\frac{\alpha}{1-\alpha}\left(S_{t}^{(1)}-S_{t}^{(2)}\right)\end{array}\right.$

Where $S_{t}^{(1)}=\alpha y_{t}+(1-\alpha) S_{t-1}{ }^{(1)}, S_{t}^{(1)}$ is the first exponential smoothing value.

Where $S_{t}^{(2)}=\alpha S_{t}^{(1)}+(1-\alpha) S_{t-1}{ }^{(2)}, S_{t}^{(2)}$ is the second exponential smoothing value.

Where $S_{0}^{(1)}, S_{0}^{(2)}$ is the average of the first few of the actual value.

\subsubsection{Sort three with Grey Prediction ${ }^{[4]}$}

With the rapid growth of population and consumption, the Agriculture, Industrial and Household Use is increasing sharply in exponential trend. The Grey Prediction is to predict with a small amount of data, and the model uses it to predict the indicators with an exponential trend. The formula of Grey Prediction is too complex to show it, which could be found in the reference ${ }^{[4]}$.

\subsubsection{Sort four with Regression Analysis ${ }^{[4]}$}

It is difficult for us to know the change trend of Water Pollution Ratio. It must have something to do with the Industrial use. We will use Pearson coefficient between Water Pollution Ratio and Industrial Use.

Regression Analysis describes the interdependent relationship between two or more variables in quantity. It is hard to estimate the trend of Water Pollution Ratio. To most developing countries, they pay more attention to economic development other than the water protection. We consider that Water Pollution Ratio must have a positive correlation with Industrial Use. Meanwhile, Pearson coefficient between the two is up to 0.9951 by data fitting. Thus, we use Regression Analysis to describe the dynamic 
nature of Water Pollution Ratio, by the known trend of Industrial Use.

The basic formula of Regression Analysis is:

$y=\beta_{0}+\beta_{1} x+\varepsilon$

Where $\beta_{0}, \beta_{1}$ is regression coefficient, $\varepsilon$ is the random error.

\subsubsection{Sort five with Logistic Curve Fitting ${ }^{[4]}$}

Throughout the economy in many countries, we find the trend of GDP per capita increase is like "S". The Logistic Curve Fitting Model is used to predict the indicator with the increasing trend of S. The formula of the model is too complex to show it, which could also be found in the reference ${ }^{[4]}$.

\subsection{Case study}

We select the historical data provided by FAOUN ${ }^{[2]}$ and then use our prediction models to get the future data. We take Population Density in Libya as an example, to show an exponential trend in Figure 1. We take GDP per capita in Libya as an example (Figure 2), to show the increasing trend of S.

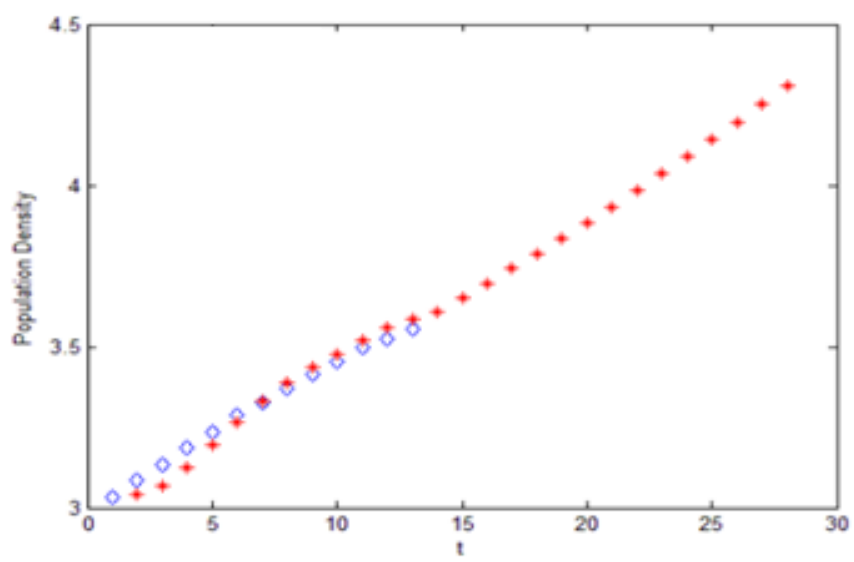

Figure 1 PopulationDensity

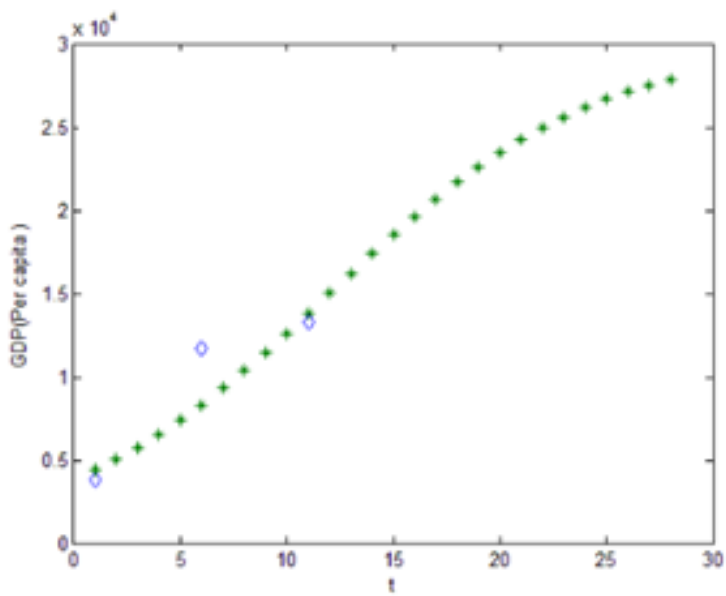

Figure 2.GDP per capita
Where the shape of box represents the historical data, the shape of star represents the predicted data.

Next, we use the predicted value of the indicators, with reference to the fuzzy comprehensive evaluation model ${ }^{[3]}$, we know the future condition of water capacity in Libya. We get the Marching Degree in the next 15 years. We show and analyze part of results in a 5-year internal, as Figure 3 shown.

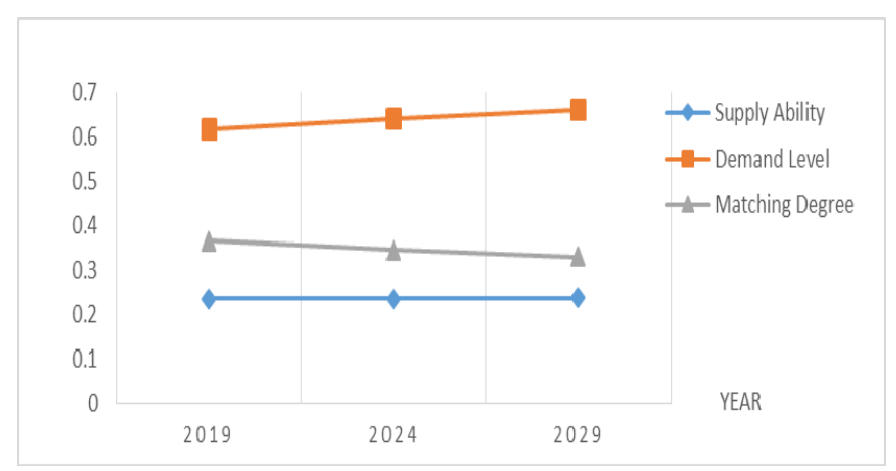

Figure 3 the predicted results

Comparing the data in the figure above, we can easily find there will be a little increase in Supply Ability, while a sharp growing in Demand Level, which worsens the Supply-and-Demand Matching Degree. We can come to the conclusion that Libya will face a more serious problem in water capacity.

\section{SUMMARY}

The paper discusses the prediction methods of indicator value which is used to evaluate sustainable development capacity of water resources .For characteristics of different data, the paper gives different prediction methods. It improves the use of historical data in the current system when assessing water capacity, which is a certain reference value. Meanwhile, it also has a guiding function on the improvement of water capacity. The case study of Libya shows the rationality of prediction methods adding to the Evaluation System.

\section{REFERENCES}

[1]. Zhaxia Li. Index System for Sustainable Utilization of Regional Water Resources [J]. Hehai University: Natural Sciences, 2007, 35(1): 81-85.

[2]. Information on:

http://www.fao.org/nr/water/aquastat/water_res/index.stm

[3]. Yizhong Zhu, Jun Xia, Ge Tan. Analysis, Prediction and Evaluation in Capacity of Water Resources in Northwest [J]. Resources Science, 2003, 25(4): 43-48.

[4]. Mathematical modeling algorithms and application exercises Answers [M]. National Defense Industry Press, 2013. 